\title{
New Challenges for Critical Care by using Point of Care Ultrasound
}

Hector R. Diaz Aguila ${ }^{1 *}$, Orlando Valdes Suarez ${ }^{2}$, Anselmo Abdo Cuza ${ }^{3}$

${ }^{1}$ Intensive Care Unit. University Hospital of Sagua la Grande. Villa Clara, Cuba. 2Intensive Care Unit.University Hospital “IvánPortuondo”. San Antonio de los Baños Artemisa, Cuba.

${ }^{3}$ Intensive Care Unit, Medical Surgical Research Center, Havana, Cuba.

\section{Abstract}

Point of Care Ultrasound has been vertiginously increased in the last years. More compact and low cost devices are available. Their fundamental objectives are to offer answers to concrete questions on possible structural or functional affections of tissues, organs or systems. Here we describe new applications of Point of Care Ultrasound. The aim of introducing Point of Care Ultrasound in Cuba is finally informed.

Keywords: Point of Care Ultrasound, Echography, Clinical Ultrasound, Ultrasonography, Critical Care.

\section{INTRODUCTION}

The use of Point of Care Ultrasound (POCUS) has been vertiginously increased in the last years. It is a concept for a quick evaluation of patients with the objective of making diagnostic or therapeutic decisions in an expedite way in any scenario of patient care [1].

Their fundamental objectives are to offer answers to concrete questions on possible structural or functional affections of tissues, organs or systems, to define the patients' initial states; to appreciate the evolution of processes or alterations, to evaluate results of treatments; and to facilitate the performance of invasive procedures[2].

\section{DISCUSSION}

POCUS is considered indispensable in the areas of Intensive Medicine and Emergencies, since it is the fifth manoeuvre of the physical exam that allows to observe the signs obtained by palpation and auscultation[3].

Such an exploration is carried out next to the patient by the assistant doctor, and its result is immediate and repeatable. It exposes the patient neither to radiations nor to any other risk; the cost is relatively low, and the presence of specialists is not required (many health centers don't have their service at any time).
The disadvantage is that results depend on the experience of the operator that carries the procedure out. With the objective of minimizing it, training courses and continuous education have been developed. They have demonstrated their validity and keep the students' abilities and the dexterities depending on the designed objectives.

There are multiple uses. Their fundamental objectives are to offer answers to concrete questions on possible structural or functional affections of tissues, organs or systems. Themainonesinclude:

- Evaluating patients with dyspnoea (immediate determination of possible heart or breathing causes)

- Confirming correct position of the tracheal tube during and after having carried the intubation out

- Providing diagnostics of pneumonia and other causes of lung condensation; determination of pleural affections (pneumothorax, pleural effusions)

- Evaluating heart function

- Assessing blood volume and fluid reanimation responses 


\section{New Challenges for Critical Care by using Point of Care Ultrasound}

- Visualizing heart contractions during cardiopulmonary reanimation as well as evaluation of possible causes of the arrest

- $\quad$ Evaluating and classifying traumatized patients

- Examining possible infection focuses in septic patient

- Proving potentials causes of abdominal pain (cholecystitis, pancreatitis, appendicitis, ectopic pregnancy, pelvic inflammation, aortic aneurysm, mesenteric ischemia)

- Determining the presence of intracranial hypertension and providing diagnostic of bone fractures or injures in soft tissues

- $\quad$ Predicting an appropriate ventilation weaning

- Evaluating the nutritional state of the patients, and many more.

It has been proven that the use of POCUS in case of urgencies by doctors or technicians diminished both the elapsed time for making an appropriate diagnosis and the stay of the patients in these services[4].

POCUS is also used as a method of clinical evaluation in space flights. Astronauts are trained in POCUS and receive health care by medical professionals from the spaceport through complex systems of telecommunications [5].

Development countries have introduced POCUS in rural medicine with satisfactory results in their application [6, 7].

POCUS is considered a system for teaching and learning anatomy and physiology "live and in real time" for medicine students in diverse universities[8].

With the objective of organizing, fostering and unifying the formation processes, and in order to draw up the objectives of POCUS development, many scientific societies have been founded: WINFOCUS (World Interactive Network Focused on Critical Ultrasound); The Canadian Society of Critical Ultrasound; CEURF (Cercle des Echographistesd'Urgence et de Réanimation Francophones); The Australian Society of Critical Echography; The Spanish Society of Critical Ultrasound; The Mexican Association of Critical Ultrasound; The Ecuadorian Society of Ultrasound in Medicine; The Chilean Society of Ultrasound in Medicine; The Venezuelan Society of Ultrasound; The Critical Ultrasound of Panama; The Uruguayan Society of Critical Ultrasound; The Colombian Society of Critical Ultrasound... Moreover, several federations are active in countries like Nicaragua, Peru, Malaysia, China, Vietnam, United Kingdom, Poland and Japan, among others.

A group of professors has set itself to introduce POCUS in Cuba, through a project including a program of a module for critical ultrasound [9], to be inserted in the curriculum for residence in Intensive Medicine and Emergencies; the publication of both articles in biomedical journals and the book "Principles of Clinical Echography in Intensive Medicine"[10]; as well as the accreditation as POCUS Instructor by the Chilean Society of Critical Medicine and Urgencies.

\section{REFERENCES}

[1] Zieleskiewicz L, Muller L, Lakhal K, Meresse Z, Arbelot C, Bertrand PM, et al. Point-of-care ultrasound in intensive care units: assessment of 1073 procedures in a multicentric, prospective, observational study. IntensiveCareMed 2015; 41(9): 1638-47.

[2] Díaz H. Clinical echography: ¿What? ¿Who? ¿What for? Medwave2016;16(8):e6547.

[3] Díaz H, López L, Valdés O. Hablemos de ultrasonido junto al paciente. Rev Cub Med Int Emerg2018; 17(3): 1-5.

[4] Adhikari S, Stolz L, Amini R, Blaivas M. Impact of point-of-care ultrasound on quality of care in clinical practice. Rep Med Imaging 2014; 7: 81-93.

[5] Lerner DJ, Chima RS, Patel K, Parmet AJ. Ultrasound guided lumbar puncture and remote guidance for potential in-flight evaluation of VIIP. Aerosp Med Hum Perform 2019;90(1):58-62.

[6] Rooney K. Point-of-Care Ultrasound as a Tool for Family Medicine. Ann Fam Med 2019;17(1). DOI: 10.1370/afm.2351.

[7] Nixon G, Blattner K, Koroheke-Rogers M, Muirhead J, Finnie WL, Lawrenson R, et al. Point-of-care ultrasound in rural New Zealand: Safety, quality 
New Challenges for Critical Care by using Point of Care Ultrasound

and impact on patient management. Aust. J. Rural [9] Díaz H. Programa de ecografía clínica básica en Health2018;26:342-9. DOI: 10.1111/ajr.12472 Medicina Intensiva. ResearchGate. 2017. DOI: 10.13140/RG.2.2.30188.46727

[8] Solomon SD, Saldana F. Point-of-care ultrasound in medical education - stop listening and look. $\mathrm{N}$ Engl J Med 2014;370(12):1083-5.

[10] Díaz H, editor. Principios de ecografía clínica en Medicina Intensiva. Bogotá: Ed. Distribuna; 2018.

Citation: Hector R. Diaz Aguila, Orlando Valdes Suarez, Anselmo Abdo Cuza. New Challenges for Critical Care by using Point of Care Ultrasound. Archives of Emergency Medicine and Intensive Care. 2019; 2(1): 15-17. Copyright: (C) 2019 Hector R. Diaz Aguila, Orlando Valdes Suarez, Anselmo Abdo Cuza. This is an open access article distributed under the Creative Commons Attribution License, which permits unrestricted use, distribution, and reproduction in any medium, provided the original work is properly cited. 